\title{
CHRONIC BRONCHITIS: A FIVE-YEAR FOLLOW-UP
}

\author{
BY \\ V. C. MEDVEI AND NEVILLE C. OSWALD \\ From the Brompton Hospital, London
}

(RECEIVED FOR PUBLICATION MAY 2, 1961)

During the past decade, many aspects of the natural history of chronic bronchitis have been subjected to scrutiny, but little attention has been paid to prognosis in terms of life expectancy. Reid and Fairbairn (1958) reviewed the sickness records of 517 postmen who had retired prematurely because of chronic bronchitis, and noted their death rate and causes of death after intervals varying from three to seven years, but no prospective study based upon full clinical and radiological examination has yet been published. From the clinical standpoint, a knowledge of the likely outcome for individual patients is most desirable and, as in other potentially fatal maladies, this may conveniently be expressed in terms of fiveyear survival. Clearly the prognosis is much better for a young bronchitic patient with mild symptoms than it is for an elderly man with advanced bronchitis and emphysema, who in addition has a greater risk of dying from a cause unrelated to the lungs, so that subdivisions by age and severity are necessary.

In this communication the fate of a group of bronchitic patients of different ages and with varying severity of symptoms was sought after a lapse of five years. Their clinical state was assessed at the beginning and end of the period, and the number of fatalities and causes of death were determined as far as possible.

\section{MATERial}

The series consists of 312 civil servants who attended the Bronchitis Clinic, Brompton Hospital, during the period March, 1951, to September, 1953. They were seen by us on behalf of the Treasury Medical Service in order that their fitness for regular service in the future might be determined. They consisted mainly of clerical officers, messengers. attendants, and industrial workers.

The initial selection was based upon sickness records, which showed either three absences from work during one year with a diagnosis of bronchitis or two such absences each lasting more than a fortnight. The records derived from the 125,000 civil servants in Greater London and were sent to the
Treasury Medical Service for referral to the clinic; in view of the large numbers involved, some relevant records may have been overlooked.

The criteria for acceptance were cough and sputum. not necessarily continuous, for at least a year which could not be attributed to any other important primary or precipitating disease of the respiratory, cardiovascular, or other systems. Disability from either breathlessness or recurrent infections was the rule, the method of selection being such that patients were called for interview as soon as they were observed to be having repeated sickness absences from bronchitis.

Altogether, 398 such patients were referred to the clinic and a full questionary, including history, physical examination, and radiography of the chest. was completed on 312 of these. At the time, a fiveyear follow-up was not contemplated, the information being included in a survey of 1,000 bronchitic patients, the results of which have already been published (Oswald, Harold, and Martin, 1953). The principal reasons for not completing the questionary on the remaining 86 patients were either that one of us (N.C.O.) was not available in the clinic to verify suitability for inclusion and accuracy of the recording or that, after the 1,000 case histories had been collected. completion of the forms was undertaken less assiduously; in neither instance was there any conscious bias in the selection of patients. When a five-year follow-up was decided upon, the choice of patients was necessarily limited to those with full records of the findings at the first visit, so that the series consists of 312 patients on whom this information was available. At the end of five years, the survivors were recalled for a second clinical and radiological examination, and the causes of death of those who had died were determined, with the aid of the Registrar-General, as far as possible.

The results of the follow-up were as follows: two hundred and three returned to the clinic for reassessment. Ninety-six died, two wrote stating that they were alive and better, four wrote stating that they were alive but worse, and seven were untraced.

Of the 96 patients who died, the certified cause of death is known in 92 . The six patients who wrote stating that they were alive and better or worse are included in the tables despite the lack of full clinical and radiological details at a follow-up examination. 
Of the seven (2.2\%) who were untraced, two were known to have emigrated. They comprised six men and one woman and were representative of the series as a whole in regard to age and severity of bronchitis at the first interview ; they have been eliminated from the analysis, leaving 305 of the 312 patients for consideration, so that the follow-up was $97.8 \%$ complete.

Since the death rates in bronchitics from all classes rise with age, comparisons of their experience must be related to the expectation among the general population of the same age living at the same time. In the following tables, the observed number of deaths has been compared with the number expected at the prevailing age and sex-specific death rates reported by the Registrar-General for England and Wales in his Statistical Reviews for the years 1951-57. Since many of these patients lived outside the county of London, particularly after retirement, the rates for England and Wales for the period 1951-57 have been used. This will understate by $12 \%$ the expected death rates from chronic bronchitis and other respiratory conditions, and the correction for Greater London would make an expected mortality of 2.7 increase to 3.0 (Table II).

\section{RESULTS}

Mortality. Fable I shows the age distribution and mortality of 305 bronchitic patients, 280 males and 25 females. Two hundred and thirtyfive, or $77 \%$, were males between the ages of 45 ,

\section{$\checkmark$ TABLE I}

DISTRIBUTION OF OBSERVED AND EXPECTED DEATHS BY AGE AND SEX: RATIO OF OBSERVED TO EXPECTED DEATHS

\begin{tabular}{|c|c|c|c|c|c|c|c|}
\hline \multirow{2}{*}{$\underset{\text { (years) }}{\text { Age }}$} & \multicolumn{4}{|c|}{ Male } & \multicolumn{3}{|c|}{ Female } \\
\hline & Total & $\begin{array}{c}\text { Observed } \\
\text { Deaths }\end{array}$ & $\begin{array}{l}\text { Expected } \\
\text { Deaths }\end{array}$ & Ratio & Total & $\underset{\text { Observed }}{\text { Deaths }}$ & $\begin{array}{l}\text { Expected } \\
\text { Deaths }\end{array}$ \\
\hline $\begin{array}{c}20-44 \\
45-54 \\
55-64 \\
65-74 \\
\text { All ages }\end{array}$ & $\begin{array}{r}24 \\
75 \\
160 \\
21 \\
280\end{array}$ & $\begin{array}{r}3 \\
16 \\
64 \\
11 \\
94\end{array}$ & $\begin{array}{r}0 \cdot 2 \\
3 \cdot 1 \\
15 \cdot 3 \\
3 \cdot 9 \\
22 \cdot 5\end{array}$ & $\begin{array}{r}15 \cdot 0 \\
5 \cdot 1 \\
4 \cdot 2 \\
2 \cdot 8 \\
4 \cdot 2\end{array}$ & $\begin{array}{r}10 \\
11 \\
4 \\
25\end{array}$ & $\frac{\overline{2}}{\overline{2}}$ & $\begin{array}{l}0.1 \\
0.2 \\
0.3 \\
\overline{0.6}\end{array}$ \\
\hline
\end{tabular}
fand 64 , as might be expected in an occupied

The ratio of observed to expected deaths was 4.2 in males and 3.3 in females, but the latter ratio is based on only two deaths. The steadily falling ratio with increasing age suggests that the outcome relative to the general experience is worse in patients who have reached the threshold of disabling illness early in adult life, presumably because of a more rapidly progressive disease.

Causes of Death.-The certified causes of death are known in 92 of the 96 fatalities. The cause of death used in the analysis was the underlying cause which started the chain of events leading to death rather than the ultimate mode of dying. For example, in a patient with terminal bronchopneumonia, death would be attributed to the pre-existing chronic bronchitis and emphysema. On the other hand, if the first cause was clearly a fatal condition in itself, such as a coronary thrombosis or cerebral vascular accident, it was accepted as such. This follows the usual convention adopted by the Registrar-General. Our assessment of the death certificates was independently checked in the Statistics Department of the Registrar-General, and therefore the assessment of the causes for observed and expected deaths was strictly comparable. The deaths were then classified as follows.

(a) Respiratory causes. In all 57 of these patients, bronchitis and/or emphysema appeared to be the underlying cause of death. Cor pulmonale was listed in seven/

(b) Cancer. Carcinoma of the bronchus accounted for four deaths, and cerebral tumour, carcinoma of the pancreas, and hypernephroma for the other three. One patient with a carcinoma of the prostate died from a coronary thrombosis.

(c) Circulatory causes. One death was due to pulmonary embolism, and 17 to ischaemic heart disease.

(d) Cerebral vascular accidents. There were three deaths due to cerebral vascular accidents.

(e) Others. Motor accident, uraemia from chronic nephritis, fractured skull, ruptured oesophageal varix, laparotomy, suicide, and ruptured aneurysm of the abdominal aorta were the causes of seven deaths.

(f) Not known. The cause was not known in four cases.

In Table II a comparison is made between the observed and expected deaths in males by systems and diseases. The two female deaths were attributed respectively to carcinoma of the bronchus and to bronchopneumonia complicating chronic bronchitis.

The excess mortality occurred principally in the respiratory group, but the number of circulatory deaths was also significantly increased. No significant excess of deaths from cancer, or cancer of the lung, was noted.

Clinical Assessment at Five Years.-In Fig. 1 the clinical assessment at five years is compared with the degree of breathlessness at the first interview, and indicates the five-year prognosis in terms of "same or better," "worse," and "dead," in three age groups and three degrees of breathlessness, as assessed at the time of the first interview. The degrees of breathlessness were defined as follows. 
TABLE II

CAUSES OF DZATH IN MALES, OBSERVED AND EXPECTED

\begin{tabular}{|c|c|c|c|c|c|c|c|c|c|}
\hline $\begin{array}{c}\text { Age } \\
\text { (Years) }\end{array}$ & & Respiratory & Cancer & $\begin{array}{c}\text { Carcinoma } \\
\text { Lung }\end{array}$ & Circulatory & $\begin{array}{l}\text { Vascular } \\
\text { Lesions } \\
\text { C.N.S. }\end{array}$ & Other & $\begin{array}{c}\text { Not } \\
\text { Stated }\end{array}$ & Total \\
\hline $\begin{array}{l}\text { 20-74: } \\
\text { Observed } \\
\text { Expected }\end{array}$ & $\begin{array}{l}\cdots \\
\cdots\end{array}$ & $\begin{array}{l}56 \\
3 \cdot 3\end{array}$ & $\begin{array}{l}6 \\
5 \cdot 7\end{array}$ & $\begin{array}{l}3 \\
\mathbf{2} \cdot 3\end{array}$ & $\begin{array}{l}18 \\
7 \cdot 6\end{array}$ & $\begin{array}{l}3 \\
2 \cdot 1\end{array}$ & $\begin{array}{l}7 \\
1 \cdot 6\end{array}$ & 4 & $\begin{array}{l}94 \\
22 \cdot 6\end{array}$ \\
\hline $\begin{array}{l}\text { 45-64: } \\
\text { Observed } \\
\text { Expected }\end{array}$ & $\ldots$ & $\begin{array}{l}50 \\
2 \cdot 7\end{array}$ & $\begin{array}{l}6 \\
4 \cdot 8\end{array}$ & $\begin{array}{l}3 \\
2 \cdot 0\end{array}$ & $\begin{array}{l}13 \\
6 \cdot 1\end{array}$ & $\begin{array}{l}2 \\
1.6\end{array}$ & $\begin{array}{l}6 \\
1 \cdot 3\end{array}$ & 3 & $\begin{array}{l}80 \\
18 \cdot 5\end{array}$ \\
\hline
\end{tabular}

Mild.-Either no breathlessness, or capable of moderate work. Breathlessness confined to heavy work.

Moderate.-Capable of light work. Breathless on walking quickly or hurrying. Able to climb 12 stairs without undue distress.
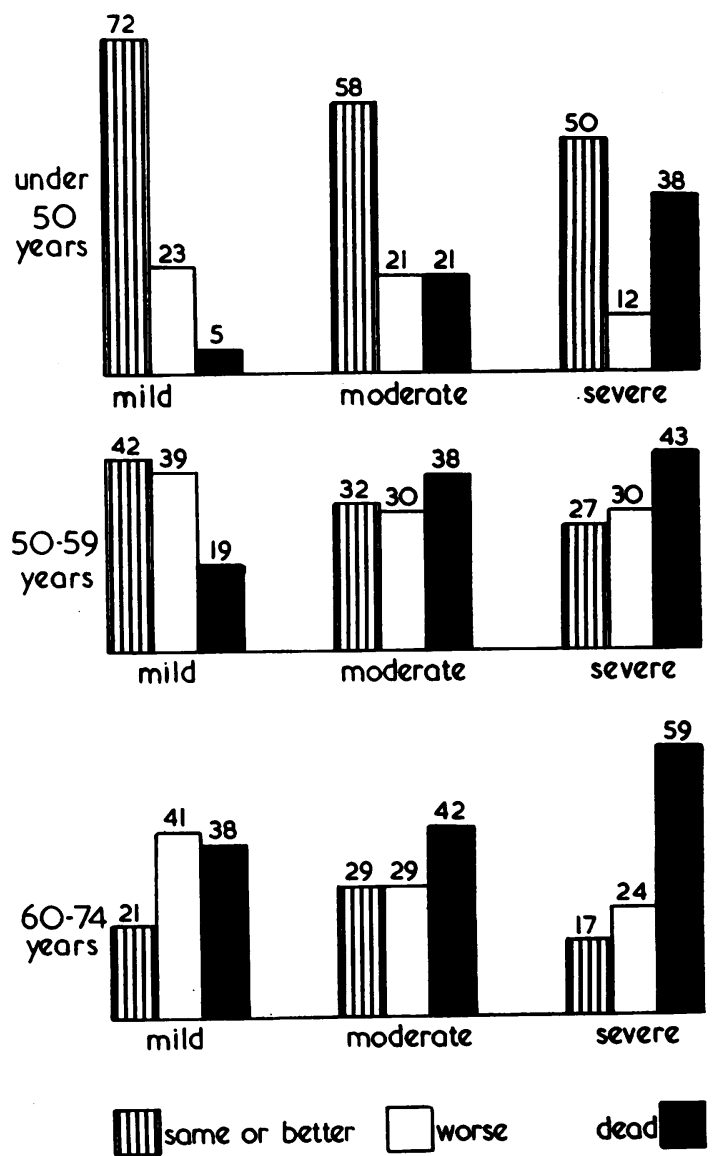

FIG. 1.-The five-year prognosis in three age groups and three degrees of breathlessness, as assessed at the first interview. Percentage distribution by age.
Severe.-Capable of sedentary work. Breathless on walking at moderate speed on the flat or climbing 12 stairs; or greater degrees of breathlessness.

The assessment of "same, better, or worse" was based on breathlessness only. Of the 305 patients, 136 had mild, 95 moderate, and 74 severe breathlessness.

The proportion of patients in whom breathlessness was the same or improved was directly related to age and to severity of symptoms at the first interview, except in the age group 60-74 in which the moderately breathless fared rather better than the mildly breathless.

The gradient of mortality is steepest in the youngest pat:ents, becoming progressively less steep in the two older groups. The serious prognostic significance of severe breathlessness in young patients is clearly seen when their mortality is compared with that of older patients with milder degrees of breathlessness.

\section{Discussion}

The ratio of observed to expected deaths in this survey was 4.2 , which is comparable with the figure of 4.5 obtained by Reid and Fairbairn (1958) in their study of bronchitic postmen. Another striking similarity exists in the distribution of certified causes of death in which our figure of $63 \%$ of respiratory deaths compares with their $58 \%$, the figure for circulatory deaths being $20 \%$ in both surveys. The respiratory and circulatory deaths together account for the excess mortality in bronchitics, and the excessive number of circulatory deaths must be accepted as significant.

The falling ratios of observed to expected deaths with increasing age are not easily explained and no other figures fre available for comparison. They suggest tha bronchitis of sufficient severity to cause sickness absences runs a more rapidly progressive course in young adults than it does in later life, and the five-year death rate of $38 \%$ 
for severely breathless bronchitics under the age / imales and 26 females. All but seven were traced, of 50 is ominous. giving a follow-up of $97.8 \%$.

The general pattern of clinical status after five years, as portrayed in Fig. 1, is to be anticipated. The proportion of patients in whom breathlessness was the same or better declined with advancing years and the death rates increased. The principal purpose of the figure is to assist in the assessment of prognosis in clinical practice. . For example, a moderately breathless bronchitic in the fifties was found to have a roughly equal chance of being the same or better, worse or dead after five years. These figures may then be taken in conjunction with the causes of death which suggest that, should he die, he has roughly an $80 \%$ probability of dying from a respiratory or circulatory cause.

\section{SUMMARY}

The fate of 312 bronchitic patients was sought after an interval of five years ; of these, 286 were There were $96(31.5 \%)$ deaths during the period, the ratio of observed to expected deaths in males being 4.2. The excess mortality occurred chiefly from respiratory causes, but circulatory deaths were also excessjive. This excess declined with increasing age

The proportion of patients in whom breathlessness was the same or better declined and the death rates increased with advancing years. The clinical state after five years in relation to age or degree of breathlessness is tabulated.

Our sincerest thanks are due to Professor Donald Reid for his assistance with the tables and his criticisms of the text, and to Miss Linda Colwell for coding and tabulating the data.

\section{REFERENCES} Oswald,

Reid, D. D., and Fairbairn, A. S. (1958). Ibid., 1, 1147.

Lancet, 2 , 